\title{
Extended Release Coated Pellet Dosage
} Form

National Cancer Institute

\section{Source}

National Cancer Institute. Extended Release Coated Pellet Dosage Form. NCI Thesaurus. Code C42918.

A pellet covered with a thin layer of substance that is designed to release active and/or inert ingredient(s) at a controlled, prolonged rate so as to reduce dosing frequency. 